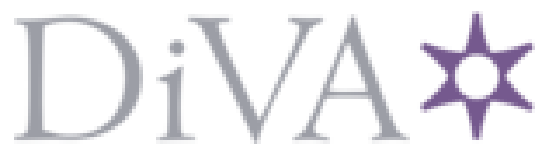

http://www.diva-portal.org

This is the published version of a paper published in Scandinavian journal of urology.

Citation for the original published paper (version of record):

Kohestani, K., Wallström, J., Dehlfors, N., Sponga, O M., Månsson, M. et al. (2019)

Performance and inter-observer variability of prostate MRI (PI-RADS version 2)

outside high-volume centres

Scandinavian journal of urology, 53(5): 304-311

https://doi.org/10.108o/21681805.2019.1675757

Access to the published version may require subscription.

N.B. When citing this work, cite the original published paper.

Permanent link to this version:

http://urn.kb.se/resolve?urn=urn:nbn:se:umu:diva-165467 


\section{Performance and inter-observer variability of prostate MRI (PI-RADS version 2) outside high- volume centres}

Kimia Kohestani, Jonas Wallström, Niclas Dehlfors, Ole Martin Sponga, Marianne Månsson, Andreas Josefsson, Sigrid Carlsson, Mikael Hellström \& Jonas Hugosson

To cite this article: Kimia Kohestani, Jonas Wallström, Niclas Dehlfors, Ole Martin Sponga, Marianne Månsson, Andreas Josefsson, Sigrid Carlsson, Mikael Hellström \& Jonas Hugosson (2019) Performance and inter-observer variability of prostate MRI (PI-RADS version 2) outside high-volume centres, Scandinavian Journal of Urology, 53:5, 304-311, DOI: 10.1080/21681805.2019.1675757

To link to this article: https://doi.org/10.1080/21681805.2019.1675757
(c) 2019 The Author(s). Published by Informa UK Limited, trading as Taylor \& Francis Group.

曲 Published online: 29 Oct 2019.

ЏIIIticle views: 724

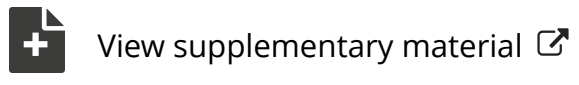

Submit your article to this journal 


\title{
Performance and inter-observer variability of prostate MRI (PI-RADS version 2) outside high-volume centres
}

\author{
Kimia Kohestani ${ }^{a, b *}$, Jonas Wallström ${ }^{c, d *}$, Niclas Dehlfors ${ }^{d}$, Ole Martin Sponga ${ }^{e}$, Marianne Månsson ${ }^{a}$, Andreas \\ Josefsson $^{\mathrm{a}, \mathrm{b}, \mathrm{f}, \mathrm{g}}$, Sigrid Carlsson ${ }^{\mathrm{a}, \mathrm{h}}$, Mikael Hellström ${ }^{\mathrm{c}, \mathrm{d}}$ and Jonas Hugosson ${ }^{\mathrm{a}, \mathrm{b}}$ \\ ${ }^{a}$ Department of Urology, Institute of Clinical Sciences, Sahlgrenska Academy, University of Gothenburg, Gothenburg, Sweden; ${ }^{\text {b Department }}$ \\ of Urology, Region Västra Götaland, Sahlgrenska University Hospital, Gothenburg, Sweden; 'Department of Radiology, Institute of Clinical \\ Sciences, Sahlgrenska Academy, University of Gothenburg, Gothenburg, Sweden; 'Department of Radiology, Region Västra Götaland, \\ Sahlgrenska University Hospital, Gothenburg, Sweden; ${ }^{e}$ Department of Radiology, Carlanderska Hospital, Gothenburg, Sweden; ${ }^{\mathrm{f}}$ Department \\ of Surgical and Perioperative Sciences, Urology and Andrology, Umeå University, Umeå, Sweden; ${ }^{9}$ Wallenberg Center for Molecular \\ Medicine, Umeå University, Umeå, Umeå, Sweden; ' Department of Surgery (Urology Service) and Department of Epidemiology and \\ Biostatistics, Memorial Sloan Kettering Cancer Center, New York, NY,USA
}

\begin{abstract}
Objective: Despite the growing trend to embrace pre-biopsy MRI in the diagnostic pathway for prostate cancer $(P C)$, its performance and inter-observer variability outside high-volume centres remains unknown. This study aims to evaluate sensitivity of and variability between readers of prostate MRI outside specialized units with radical prostatectomy (RP) specimen as the reference standard.

Materials and methods: Retrospective study comprising a consecutive cohort of all 97 men who underwent MRI and subsequent RP between January 2012 and December 2014 at a private hospital in Sweden. Three readers, blinded to clinical data, reviewed all images (including 11 extra prostate MRI to reduce bias). A tumour was considered detected if the overall PI-RADS v2 score was 3-5 and there was an approximate match (same or neighbouring sector) of tumour sector according to a 24 sector system used for both MRI and whole mount sections.

Results: Detection rate for the index tumour ranged from 67 to $76 \%$, if PI-RADS 3-5 lesions were considered positive and $54-66 \%$ if only PI-RADS score 4-5 tumours were included. Detection rate for aggressive tumours (GS $\geq 4+3$ ) was higher; $83.1 \%$ for PI-RADS 3-5 and 79.2\% for PI-RADS 4-5. The agreement between readers showed average $\kappa$ values of 0.41 for PI-RADS score 3-5 and 0.51 for PI-RADS score 4-5. Conclusions: Prostate MRI evidenced a moderate detection rate for clinically significant PC with a rather large variability between readers. Clinics outside specialized units must have knowledge of their performance of prostate MRI before considering omitting biopsies in men with negative MRI.
\end{abstract}

ARTICLE HISTORY

Received 26 March 2019

Revised 20 August 2019

Accepted 29 September 2019

\section{KEYWORDS}

Prostatic neoplasms; magnetic resonance imaging; radical prostatectomy; interobserver agreement; observer variation

\section{Introduction}

Prostate cancer $(\mathrm{PC})$ forms a major public health concern in Western society $[1,2]$. The standard method to diagnose PC has been transrectal ultrasound (TRUS)-guided systematic biopsies of the prostate. However, a major drawback with this approach is the risk of over-detection of clinically nonsignificant PC due to low specificity of elevated PSA and high prevalence of indolent tumours in the prostate [3-7]. The low specificity of PSA also implies that many men with elevated PSA-levels undergo unnecessary prostate biopsy, with its concomitant risks of bleeding, infection, and hospitalization. Hence, a better diagnostic approach is urgently needed. Therefore, pre-biopsy magnetic resonance imaging (MRI) of the prostate and performing (targeted) biopsies only in men with suspicious MRI is a rapidly growing trend in the diagnostic pathway [8].
Prostate MRI performed at high-volume centres and reported by experienced radiologists has shown promising results in reducing the number of unnecessary biopsies and reducing over-diagnosis [9]. The PRECISION trial, a multicentre study randomizing men to MRI with or without biopsies targeted to tumour-suspicious areas versus standard TRUS-guided systematic biopsies, showed that the MRI-arm was superior with more clinically significant PC detected, fewer men undergoing biopsy, and fewer clinically insignificant PC detected [10].

With the increased use of prostate MRI outside specialized units, it is relevant to question if the promising results from high-volume centres can be reproduced in a less experienced setting. In a routine clinical care study, substantial variation was reported in PI-RADS-score assignment and significant cancer yield among radiologists [11]. Diagnostic 
accuracy of pre-biopsy $\mathrm{MRI}$ in detecting clinically significant PC ranges from 44 to $87 \%$ and with a negative predictive value (NPV) ranging between 63 and 98\% [12,13].

Until recently, due to the large variability in NPV, most guidelines on PC did not recommend routine use of prebiopsy MRI in biopsy-naïve patients [14]. Now, we find a shift, however. The updated 2019 EAU (European Association of Urology) Guidelines recommend performing MRI in both biopsy-naïve patients and previously biopsied patients with clinical suspicion of PC [15]. There is an ongoing debate about whether it is safe to omit biopsies in MRI-negative men.

To standardize interpretation and reporting of prostate MRI, the European Society of Urogenital Radiology (ESUR) and the American College of Radiology (ACR) developed the Prostate Imaging Reporting and Data System version 2 (PIRADS v.2) [16]. PI-RADS v.2 has been shown to have low specificity $[17,18]$ and a moderate inter-reader reproducibility [18-21], which are major concerns to consider before MRI can safely be used in the routine.

The purpose of this study was to evaluate the performance and variability between readers of prostate MRI outside specialized units with prostatectomy (RP) specimen as the reference standard.

\section{Materials and methods}

\section{Study design and participants}

All men who consecutively underwent retropubic radical prostatectomy (RRP) or robotic-assisted radical prostatectomy (RARP) between 1 January 2012 and 31 December 2014 and who also underwent preoperative MRI of the prostate were identified $(n=107)$. These men were treated at a private hospital in Sweden where pre-surgical MRI was incorporated into routine care early on. However, patients were selected for surgery based upon findings at TRUS-guided biopsies. MRI was performed in the majority of patients (73.2\%) before the diagnostic biopsies. MRI information was not used to select patients but for strategic planning of the surgery (e.g. degree of nerve-sparing). Of eligible patients, ten were excluded: 1 (neoadjuvant hormonal therapy); 1 (non-tumour finding at final pathology); 5 (MR images unavailable for review); and 3 (poor quality of MRIs). To reduce confirmation bias, 11 additional MRIs judged as normal and from men with benign pathology at TRUS biopsies and/or TURP were added and randomly mixed to the list for review. Readers were informed of the incorporation of 'normal' MRIs in the study but not the total number. These 11 extra cases were not included in the analysis, resulting in a final study population of 97 patients of

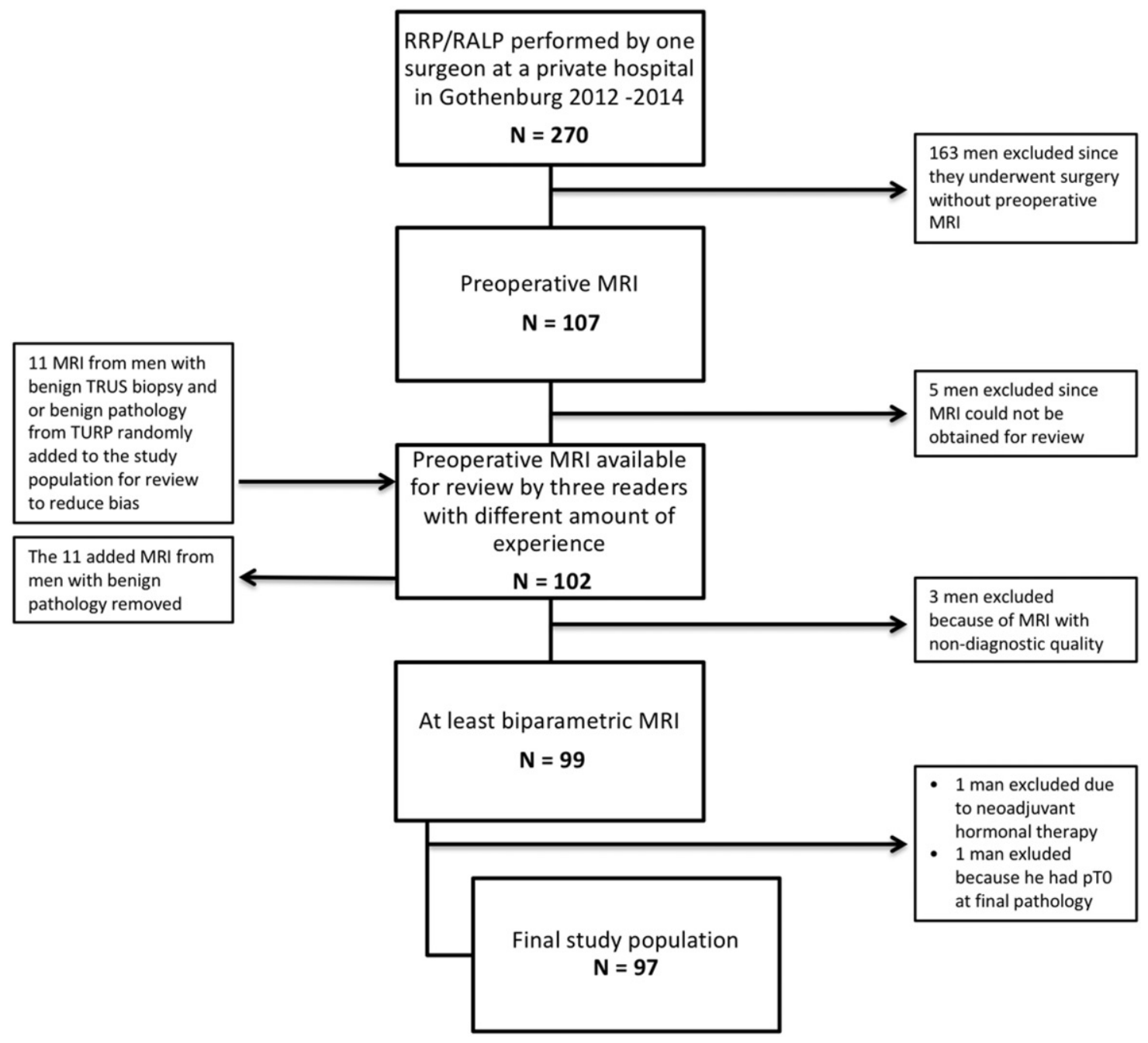

Figure 1. Flow chart of the patients included in the study. 
which 84 were operated by RRP and 13 by RARP (Figure 1). The study was approved by The Regional Ethical Review Board in Gothenburg (registration number 515-14).

\section{$M R I$ and review}

MRI examinations were performed at 16 different hospitals (median time 1 month prior to RP). The majority of examinations (66 of 97) were performed using a 1.5-T scanner (GE Medical Systems Signa HDe) with a pelvic phased-array coil in the same hospital where the men underwent surgery. Pulse sequences included multiplanar fast spin echo (FSE) T2-weighted imaging, axial diffusion-weighted imaging (DWI), and axial dynamic contrast-enhanced (DCE) T1weighted imaging with DCE imaging as the final sequence. DWI imaging included a high $b$ value of $1500 \mathrm{~s} / \mathrm{mm}^{2}$. Due to scanner restrictions, only two b-values were acquired ( 0 and $1500 \mathrm{~s} / \mathrm{mm}^{2}$ ) and used to construct the apparent diffusion coefficient (ADC)-map. DCE imaging was performed after $0.1 \mathrm{mmol} / \mathrm{kg}$ gadoterate meglumine (Dotarem, Gothia Medical), administered as an intravenous bolus injection via a power injector (Medtron, Gothia Medical).
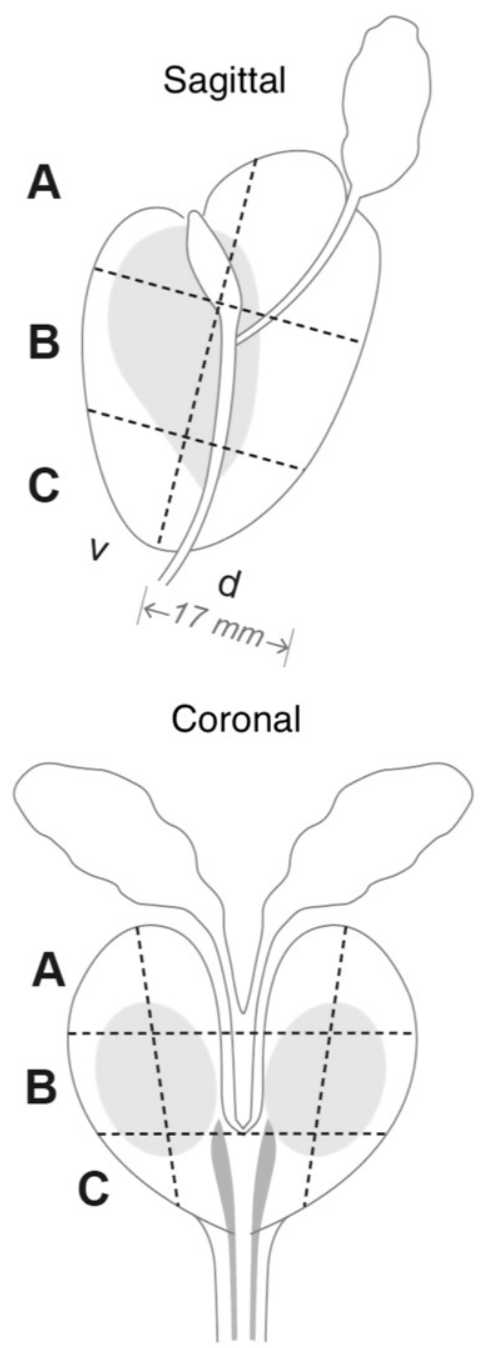

Figure 2. The 24-sector template, based on the Swedish National PC Guidelines, used to record the anatomical localization of the MRI-lesions and the tumour localization on the whole mount sections. The index tumours were considered detected if there was a lesion with a PI-RADS score $3-5$ described in the same or neighbouring sector (approximate match). $A=$ base; $B=$ mid-gland; $C=$ apex; $v=$ ventral; $d=$ dorsal.
Of 97 examinations, 12 were performed before the publication of PI-RADSv1 and all were performed without DCE. After PI-RADSv1 was published, the main site protocol was changed to include DCE. At the external sites, DCE was performed according to local preferences. One-third of examinations (34 of 97) were bi-parametric and did not include DCE. MRI characteristics are reported in Supplementary Table 1. Image interpretation was performed using SECTRA PACS and interpretation of DCE images was based on source images alone without post-processing.

A retrospective $M R I$ review of all the images was performed and reported by three readers independently of each other. Readers were blinded to original MRI reports, clinical data, and pathology results. In addition, one reader (reader 1) performed a secondary analysis after unblinding of pathology results in cases assessed by all readers to be MRI-negative.

Each reader reported a maximum of three lesions per case using a structured reporting template based on the PIRADS version 1 guidelines, except for lesion mapping. Lesions were mapped on a 24-sector template adopted in Sweden as the national standard for pathology and radiology
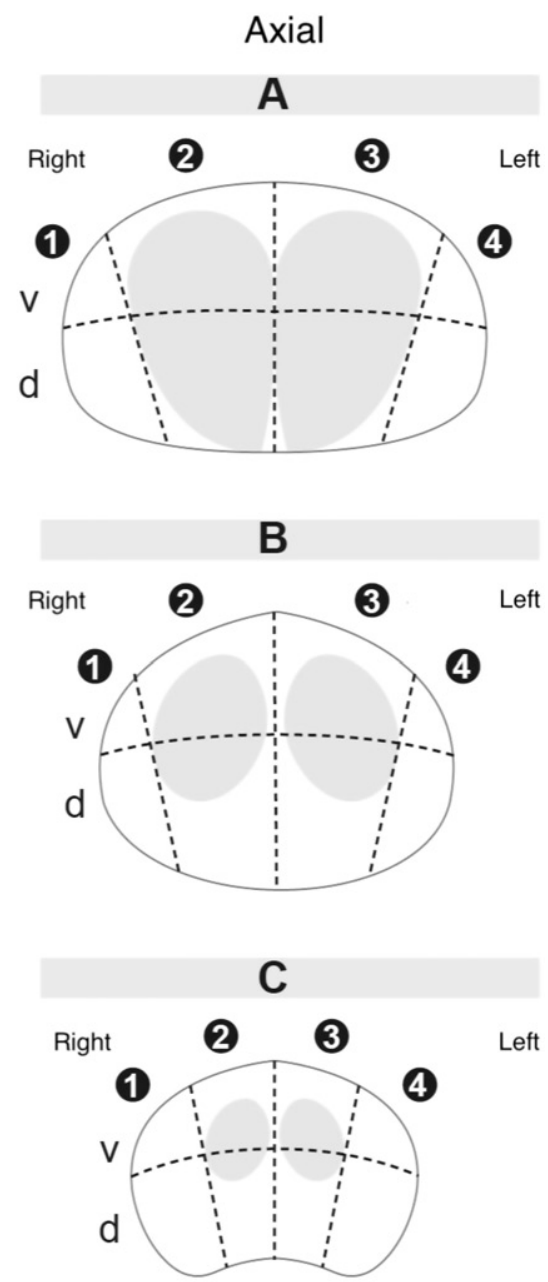
reports (Figure 2). Following the review, reader 1 assigned each lesion to the relevant prostate zone before using a computer script converting the PI-RADSv1 to PI-RADSv2 overall scores. The MRI index lesion was defined as the lesion with the highest overall PI-RADSv2 score. In case several lesions with the same PI-RADS score were described, the largest one was considered the index lesion.

Table 1. Patient and tumour characteristics, both pre- and postoperatively. Numbers represent frequency (\%) or median (inter quartile range).

\begin{tabular}{|c|c|c|}
\hline Preoperative characteristic & Median & $(\mathrm{IQR})$ \\
\hline Age at surgery, years & 61 & $(56 ; 65)$ \\
\hline PSA at diagnosis, $\mathrm{ng} / \mathrm{mL}$ & 6.4 & $(4.3 ; 9.7)$ \\
\hline $\begin{array}{l}\text { TRUS-estimated prostate volume, cc } \\
\text { Missing } n=4\end{array}$ & 31 & $(25 ; 42)$ \\
\hline $\begin{array}{l}\text { PSA density } \\
\text { Missing } n=4\end{array}$ & 0.21 & $(0.13 ; 0.35)$ \\
\hline $\begin{array}{l}\text { Total number of biopsy cores taken } \\
\text { Missing } n=2\end{array}$ & 10 & $(10 ; 12)$ \\
\hline $\begin{array}{l}\text { Number of positive biopsy cores } \\
\text { Missing } n=4\end{array}$ & 4 & $(2 ; 6)$ \\
\hline $\begin{array}{l}\text { Percentage positive biopsy cores (\%) } \\
\quad \text { Missing } n=4\end{array}$ & $40 \%$ & $(20 \% ; 65 \%)$ \\
\hline $\begin{array}{l}\text { Total cancer core length, } \mathrm{mm} \\
\quad \text { Missing } n=3\end{array}$ & 13 & $(6 ; 25)$ \\
\hline \multicolumn{3}{|l|}{ Clinical stage } \\
\hline T1c & 69 & $(71.1 \%)$ \\
\hline $\mathrm{T} 2$ & 26 & $(26.8 \%)$ \\
\hline T3-4 & 0 & $(0 \%)$ \\
\hline Missing & 2 & $(2.1 \%)$ \\
\hline \multicolumn{3}{|l|}{ Biopsy Gleason score } \\
\hline $3+3$ & 41 & $(42.3 \%)$ \\
\hline $3+4$ & 36 & $(37.1 \%)$ \\
\hline $4+3$ & 11 & $(11.3 \%)$ \\
\hline$\geq 4+4$ & 9 & $(9.3 \%)$ \\
\hline Postoperative outcomes & $\mathrm{n}$ & $(\%)$ \\
\hline \multicolumn{3}{|l|}{ Opertion technique } \\
\hline Retropubic radical prostatectomy & 84 & $(86.6)$ \\
\hline Robot-assisted laparoscopic prostatectomy & 13 & (13.4) \\
\hline \multicolumn{3}{|l|}{ Pathological stage } \\
\hline pT2 & 61 & $(62.9 \%)$ \\
\hline pT3 & 36 & $(37.1 \%)$ \\
\hline \multicolumn{3}{|l|}{ Phatological Gleason score } \\
\hline Small/insignificant $3+3(<10 \mathrm{~mm})$ & 5 & $(5.2 \%)$ \\
\hline $3+3(\geq 10$ millimetre or unknown size) & 18 & $(18.6 \%)$ \\
\hline $3+4$ & 48 & $(49.5 \%)$ \\
\hline $4+3$ & 17 & $(17.5 \%)$ \\
\hline$\geq 4+4$ & 9 & $(9.3 \%)$ \\
\hline \multicolumn{3}{|l|}{$\bar{T}$ Tumour diameter $>10$ millimetre } \\
\hline Yes & 75 & $(77.3 \%)$ \\
\hline No & 5 & $(5.2 \%)$ \\
\hline Missing & 17 & $(17.5 \%)$ \\
\hline \multicolumn{3}{|l|}{ Surgical margins } \\
\hline Positive & 18 & $(18.6 \%)$ \\
\hline Negative & 76 & $(78.4 \%)$ \\
\hline
\end{tabular}

Radical prostatectomy (RP) pathology, prostate scheme, and correlation to MRI-lesions

The RP specimens were processed and evaluated at the Department of Pathology, Unilabs Skövde (Skaraborgs Sjukhus, Skövde, Sweden). Size and Gleason Score (GS) of the three largest tumour foci on the RP specimens were recorded from the pathology reports and scanned whole mounts slides. This was done by one of the investigators (K.K), who also recorded the localization of each tumour according to the same 24-sector template as described above. If several tumours were found, the index tumour was defined as the tumour with the highest GS or the largest one if several tumours with the same GS were found. Two of the investigators (K.K and J.W) compared the localization of the index tumour with MRI reports. The index tumours were considered detected if there was a lesion with a PI-RADS score 3-5 described in the same or neighbouring sector (approximate match).

\section{Statistical analysis}

Descriptive statistics were applied to compare the demographics between groups of patients with MRI-negative tumours (defined as not assessed by any of the readers) and patients with MRI-positive tumours. Characteristics of the missed tumours are described. Detection rate of index tumour was calculated for each reader separately and for overall detection.

Inter-observer agreement between each pair of readers for lesions was evaluated using Cohen's $\kappa$ coefficient and assessed according to Landish and Coch [22], considering slight agreement as $\kappa 0.01-0.20$, fair agreement $\kappa 0.21-0.40$, moderate agreement $\kappa 0.41-0.60$, substantial agreement, $\kappa$ $0.61-0.80$, and almost perfect agreement $\kappa 0.81-0.99$. The $\kappa$ coefficient is an index of agreement corrected for chance and thus a high prevalence of a given observation can produce a counter-intuitive low $\kappa$ coefficient even if the interobserver agreement is almost perfect.

Analyses were performed using SPSS (version 24) and R Statistical Software (Version 3.3.1; Foundation for Statistical Computing, Vienna, Austria).

\section{Results}

Patient- and tumour characteristics before and after RP are shown in Table 1.

Table 2. Index tumour reported as PI-RADS 3-5 by the three readers separately and average index tumour detection rate. The readers had different previous experience of reporting prostate MRI. Prior to the review, a conformity meeting was held but there was no structured didactic session. Readers 1 and 3 were board-certified radiologists with previous experience of approximately 200 and 300 prostate MRI cases, respectively. They had both attended the ESUR prostate MRI workshop prior to the study. Reader 2 was a resident in radiology with previous experience of approximately 50 cases.

\begin{tabular}{|c|c|c|c|c|}
\hline Gleason score (GS) & $\begin{array}{c}\text { Reader } 1 \\
\text { Missing }=1\end{array}$ & $\begin{array}{c}\text { Reader } 2 \\
\text { Missing }=1\end{array}$ & $\begin{array}{c}\text { Reader } 3 \\
\text { Missing }=0\end{array}$ & $\begin{array}{c}\text { Average detection } \\
\text { rate }(\%)\end{array}$ \\
\hline $3+3(<10 \mathrm{~mm}) n=5$ & $40 \%(2)$ & $0 \%(0)$ & $40 \%(2)$ & 26.7 \\
\hline $3+3(\geq 10 \mathrm{~mm} /$ unknown size) $n=18$ & $83.3 \%(15)$ & $58.8 \%(10)$ missing $=1$ & $72.2 \%(13)$ & 70.4 \\
\hline $3+4 n=48$ & $70.8 \%(34)$ & $70.8 \%(34)$ & $77.1 \%(37)$ & 72.9 \\
\hline $4+3 n=17$ & $88.2 \%(15)$ & $70.6 \%(12)$ & $82.4 \%(14)$ & 80.4 \\
\hline$\geq 4+4 n=9$ & $87.5 \%(7)$ missing $=1$ & $88.9 \%(8)$ & $88.9 \%(8)$ & 88.4 \\
\hline$\overline{\text { All }}$ GS pT2 $n=61$ & $75.0 \%(45)$ missing $=1$ & $61.7 \%(37)$ missing $=1$ & $73.8 \%(45)$ & 70.2 \\
\hline All GS pT3 $n=36$ & $77.8 \%(28)$ & $75.0 \%(27)$ & $80.6 \%(29)$ & 77.8 \\
\hline Total $n=97$ & $76.0 \%(73)$ & $66.7 \%(64)$ & $76.3 \%(74)$ & 73.0 \\
\hline
\end{tabular}

Numbers represents percent (n). 
There were no noteworthy differences between the groups of men with MRI-positive and MRI-negative index tumours (not identified by any of the readers) with respect to age, PSA level, prostate volume, or largest tumour diameter at pathology (Supplementary Table 2). Median PSA density (PSAD) was lower in the MRI-negative group, 0.11 (IQR 0,$15 ; 0,35)$ compared to the MRI-positive group, PSAD 0.21 (IQR 0,08; 0,25).

Average index tumour detection rate for the readers was 73\% (range 67-76\%) if lesions with PI-RADS score 3-5 were considered and $61 \%$ (range $54 \%-66 \%$ ) if PI-RADS score $4-5$ were considered. Average detection rate for aggressive tumours (GS $\geq 4+3$ ) was higher; $83 \%$ (range 77-88\%) for PI-RADS 3-5 and 79\% (range 69-85\%) for PI-RADS 4-5 (Tables 2 and 3).

There was fair to moderate agreement for pairwise combination of readers with lesions PI-RADS $\geq 3$ with $\kappa$ coefficients of $0.38(95 \% \mathrm{Cl} 0.18-0.58), 0.31(95 \% \mathrm{Cl} 0.09-0.53)$, and 0.54 (95\% Cl 0.35-0.72), and moderate agreement for pairwise combinations of readers with lesions PI-RADS $\geq 4$ with $\kappa$ coefficients of $0.50(95 \% \mathrm{Cl} 0.32-0.67), 0.49(95 \% \mathrm{Cl}$ $0.31-0.68)$, and 0.54 (95\% Cl 0.37-0.71) (Table 4).

In 11 men, index tumour was missed by all readers: three men had GS $3+3$ (including one man with 2 mm GS $3+3$ ); six men had GS $3+4$; one man had GS $4+3$ and one man had GS $4+5$. Complete characteristics of these index tumours that no reviewer reported are shown in Table 5 . Three of these men had a second or third significant tumour correctly identified by all readers including the man with GS $4+5$.

Of the missed index tumours, five were located in the apex, two in the mid gland, and four in the base of the prostate. Nine were peripheral zone tumours.

After unblinding of pathology results, reader 1 could retrospectively identify four of 11 previously missed index tumours ( 1 centrally around urethra; 1 in transition zone; 2 in peripheral zone). Further, another 11 men had MRI where only one of the readers reported the index tumour, Table 6.

There were 23 false-positive MRI lesions in the group of 97 men with proven PC. False positives were defined as PIRADS 3-5 without any correlating tumour in the prostatectomy specimen. Of these, 2 lesions were scored PI-RADS 5 , 13 lesions PI-RADS 4, and 8 lesions PI-RADS 3. The number of false-positive lesions per reader was 6 lesions (reader 1), 5 lesions (reader 2), and 12 lesions (reader 3), with a positive predictive value (PPV) of 92\%, 92\%, and $86 \%$, respectively.
In the sample of 11 men with benign histology, reader 1 reported one suspicious lesion (PI-RADS 3-5), reader 2 reported two lesions, and reader 3 reported eight lesions.

\section{Discussion}

The aim of this study was to evaluate performance and interobserver variability between readers of prostate-MRI outside high-volume clinics, using histology from RP as reference standard. Detection rate for the index tumour ranged from $67-76 \%$ if PI-RADS 3-5 lesions were considered positive and $54-66 \%$ if only PI-RADS score 4-5 tumours were included. Detection rate for aggressive tumours (GS $\geq 4+3$ ) was higher; $83.1 \%$ for PI-RADS 3-5 and $79.2 \%$ for PI-RADS 4-5.

In a study by Greer et al., comparing detection of index lesions across five body radiologists from two different institutions with prostatectomy specimens as a reference standard, the average sensitivity for detecting index lesions defined as GS7 or above was $91 \%$ [23]. This study included more high-grade PC (approximately $50 \%$ GS $4+3$ or above), all imaging was performed at $3 \mathrm{~T}$ at a single institution and used moderately to highly experienced body radiologists, which may account for the higher reported detection rate. In a meta-analysis including 526 patients from seven studies, the pooled sensitivity for MRI detection of clinically significant PC was lower, 74\% [24].

Regarding the 11 men whose index tumour was not identified by any of the readers, three had GS $3+3$ tumours $(27 \%)$ and one of these tumours was only $2 \mathrm{~mm}$ in diameter and thus considered clinically insignificant. The remaining eight men all had GS $\geq 3+4$ and seven of these had multifocal disease. Of those with multifocal disease, another significant tumour (GS $\geq 3+4$ ) was correctly identified by all readers in three cases. Borofsky et al. reported a prospective detection rate of $84 \%$ for the two largest clinically significant lesions when correlating MRI reports to prostatectomy specimens [25]. This study included 162 lesions in 100 patients corresponding to 1 GS $3+3$ tumour, 97 GS $3+4 / 4+3$ tumours, and $64 \mathrm{GS} \geq 8$ tumours. When re-reading the MRI, a majority of missed tumour lesions were multifocal and 17

Table 4. Agreement for pairwise combination of readers with lesions PI-RADS $\geq 3$ and $P I-R A D S \geq 4$.

\begin{tabular}{lccc}
\hline PI-RADS v.2.limit & Reader 1 vs. 2 & Reader 1 vs. 3 & Reader 2. vs. 3 \\
\hline At least PI-RADS 3 & $0.38(0.18,0.58)$ & $0.31(0.09,0.53)$ & $0.54(0.35,0.72)$ \\
At least PI-RADS 4 & $0.50(0.32,0.67)$ & $0.49(0.31,0.68)$ & $0.54(0.37,0.71)$ \\
\hline
\end{tabular}

Numbers represents Cohen's $\kappa$ coefficient ( $95 \%$ confidence interval).

Table 3. Index tumour reported as PI-RADS 4-5 by the three readers separately and average index tumour detection rate.

\begin{tabular}{|c|c|c|c|c|}
\hline Gleason score (GS) & $\begin{array}{c}\text { Reader } 1 \\
\text { Missing }=1\end{array}$ & $\begin{array}{c}\text { Reader } 2 \\
\text { Missing }=1\end{array}$ & $\begin{array}{c}\text { Reader } 3 \\
\text { Missing }=0\end{array}$ & $\begin{array}{c}\text { Average detection } \\
\text { rate }(\%)\end{array}$ \\
\hline $3+3(<10 \mathrm{~mm}) \mathrm{n}=5$ & $20.0 \%(1)$ & $0 \%(0)$ & $0 \%(0)$ & 6.7 \\
\hline $3+3(\geq 10 \mathrm{~mm} /$ unknown size) $n=18$ & $66.7 \%(12)$ & $29.4 \%(5)$ missing $=1$ & $50.0 \%(9)$ & 48.7 \\
\hline $3+4 n=48$ & $54.2 \%(26)$ & $60.4 \%(29)$ & $68.8 \%(33)$ & 61.1 \\
\hline $4+3 n=17$ & $82.4 \%(14)$ & $64.7 \%(11)$ & $82.4 \%(14)$ & 76.5 \\
\hline$\geq 4+4 n=9$ & $87.5 \%$ (7) missing $=1$ & $77.8 \%(7)$ & $88.9 \%(8)$ & 84.7 \\
\hline$\overline{\text { All }}$ GS pT2 $n=61$ & $55.0 \%(33)$ missing $=1$ & $48.3 \%(29)$ missing $=1$ & $60.7 \%(37)$ & 54.7 \\
\hline All GS pT3 $n=36$ & $75.0 \%(27)$ & $63.9 \%(23)$ & $75.0 \%(27)$ & 71.3 \\
\hline Total $n=97$ & $62.5 \%(60)$ & $54.2 \%(52)$ & $66.0 \%(64)$ & 60.9 \\
\hline
\end{tabular}


Table 5. Characteristics of index tumours with negative preoperative MRI, characteristics of index tumours that no reader reported on MRI.

\begin{tabular}{|c|c|c|c|c|c|c|c|c|c|c|}
\hline $\begin{array}{l}\text { Age at } \\
\text { surgery (years) }\end{array}$ & $\begin{array}{c}\mathrm{PSA} \\
(\mathrm{ng} / \mathrm{mL})\end{array}$ & $\begin{array}{l}\text { Biopsy } \\
\text { GS }\end{array}$ & $\begin{array}{l}\text { Pathological } \\
\text { stage }\end{array}$ & $\begin{array}{c}\text { Pathological } \\
\text { GS }\end{array}$ & $\begin{array}{l}\text { Localization of } \\
\text { index tumour }\end{array}$ & $\begin{array}{l}\text { Size of index } \\
\text { tumour }(\mathrm{mm})\end{array}$ & SVI & ECE & PSM & $\begin{array}{l}\text { Tumour } 2 \text { or } \\
3 \text { detected }^{*}\end{array}$ \\
\hline 71 & 8 & $3+3$ & pT2c & $3+4$ & 4 Cvd & 10 & No & No & No & \\
\hline 66 & 4 & $3+4$ & pT2c & $3+4$ & $1 \mathrm{Cd}$ & $14 \times 9$ & No & No & No & \\
\hline 67 & 5 & $3+3$ & pT2c & $3+4$ & $12 \mathrm{BCvd}$ & $19 \times 16$ & No & No & No & \\
\hline 65 & 8 & $3+4$ & рT3a & $3+4$ & $1234 \mathrm{Cv}$ & $22 \times 11$ & No & Yes & Yes & Yes, GS $3+4$ \\
\hline 64 & 3 & $3+4$ & рT3a & $3+4$ & 1Avd & $13 \times 4$ & No & Yes & No & \\
\hline 63 & 22 & $3+4$ & pT3b & $4+5$ & $1 \mathrm{Ad}$ & Unknown & Yes & Yes & Yes & Yes, GS $3+4$ \\
\hline 61 & 6 & $3+3$ & pT2a & $3+3$ & $1 \mathrm{Cd}$ & $15 \times 4$ & No & No & No & \\
\hline 59 & 4 & $3+3$ & pT2c & $3+3$ & $1 \mathrm{Cd}$ & $8 \times 5$ & No & No & No & \\
\hline 56 & 7 & $3+4$ & рT3a & $3+4$ & 4Bvd & $16 \times 8$ & No & Yes & No & Yes, GS $3+4$ \\
\hline 56 & 4 & $3+3$ & pT2 & $4+3$ & $4 A B C v$ & $18 \times 8$ & No & No & No & \\
\hline 52 & 3 & $3+3$ & pT2a & $3+3$ & 1Avd & 2 & No & No & No & \\
\hline
\end{tabular}

*One or more of the readers described a lesion where the second or third tumour on the specimen. GS: Gleason score; SVI: seminal vesicle invasion; ECE: extracapsular extension; PSM: positive surgical margins.

TABLE 6. Characteristics of index tumours with negative preoperative MRI, characteristics of index tumours that only one of three readers reported on MRI.

\begin{tabular}{|c|c|c|c|c|c|c|c|c|c|}
\hline $\begin{array}{l}\text { Age at surgery } \\
\text { (years) }\end{array}$ & $\begin{array}{c}\text { PSA } \\
(\mathrm{ng} / \mathrm{mL})\end{array}$ & $\begin{array}{c}\text { Biopsy } \\
\text { GS }\end{array}$ & $\begin{array}{l}\text { Pathological } \\
\text { stage }\end{array}$ & $\begin{array}{c}\text { Pathological } \\
\text { GS }\end{array}$ & $\begin{array}{l}\text { Localization of } \\
\text { index tumour }\end{array}$ & $\begin{array}{l}\text { Size of index } \\
\text { tumour }(\mathrm{mm})\end{array}$ & SVI & ECE & PSM \\
\hline 73 & 5 & $3+4$ & $\mathrm{pT} 2 \mathrm{~b}$ & $3+4$ & $1 \mathrm{ABd}$ & $16 \times 8$ & No & No & No \\
\hline 71 & 10 & $4+5$ & pT2c & $4+3$ & $4 A B C v d$ & Unknown & No & No & Yes \\
\hline 65 & 4 & $3+3$ & pT2c & $3+4$ & $12 \mathrm{Bd}$ & Unknown & No & No & No \\
\hline 62 & 4 & $3+3$ & pT2c & $3+4$ & 1 Avd & $10 \times 7$ & No & No & No \\
\hline 64 & 4 & $3+4$ & pT2c & $3+4$ & $34 \mathrm{BCd}$ & $20 \times 8$ & No & No & No \\
\hline 62 & 4 & $3+3$ & pT2c & $3+3$ & $4 A B C v d$ & $3 \times 3$ & No & No & No \\
\hline 60 & 4 & $3+3$ & рT3a & $3+4$ & $34 \mathrm{BCvd}$ & Unknown & Yes & Yes & No \\
\hline 59 & 6 & $3+3$ & рT3a & $3+3$ & $4 \mathrm{BCd}$ & Unknown & No & Yes & Yes \\
\hline 59 & 4 & $3+3$ & pT2a & $3+3$ & $34 \mathrm{Bv}$ & $19 \times 9$ & No & No & No \\
\hline 58 & 4 & $3+3$ & pT2 & $3+3$ & $2 \mathrm{Bd}$ & $9 \times 5$ & No & No & No \\
\hline 45 & 30 & $3+4$ & pT3b & $4+3$ & 1234ABCvd & Unknown & Yes & Yes & Yes \\
\hline
\end{tabular}

GS: Gleason score; SVI: seminal vesicle invasion; ECE: extracapsular extension; PSM: positive surgical margins.

out of the 26 missed lesions were GS $3+4$ (65\%). None were GS 6. Like our study, a lower PSAD was noted in the group of men with missed tumours. Multi-focality and low PSAD might be related to difficulties of visualizing tumours on MRI but this needs to be further studied.

There was a large variation in the number of false positives reported by the three readers. The reader with the highest number of false positives also had the best index tumour detection rate. At the same time, this reader reported over 70\% PI-RADS 3-5 lesions in the added sample with negative MRI:s, indicating that this reader had a bias towards overcalling lesions.

We report fair to moderate pairwise inter-observer agreement for lesions stratified as either PI-RADS $\geq 3$ or PI-RADS $\geq 4$ with $\kappa$ of 0.41 and 0.51 . In a study by Muller et al., a moderate $\kappa$ value of 0.46 for scoring of predefined suspicious lesions according to PI-RADS v.2 was reported [21]. However, in our study, suspicious lesions were not presented to the radiologists beforehand, adding another level of authenticity to resemble the daily workflow. In an article by Sonn et al., a substantial variation was found across radiologists with different reporting volumes in a specialized centre reporting according to PI-RADS v.2, concluding that internal validation of $\mathrm{MRI}$ is warranted before widespread adoption [11]. In our study, we found a moderate agreement level between readers despite a heterogeneous MRI population, varying radiologist experience, and a low-volume setting.

Interestingly, Rosenkrantz et al. found that the learning curve in prostate tumour detection among six second-year residents largely reflected self-directed learning with less effect of continual feedback and a plateau after a moderate number of cases, approximately 40 [26]. In our study, the two board-certified readers who had read $>200$ cases performed somewhat better (average detection rate 76\%) than the resident who had read approximately 50 cases (average detection rate $67 \%$ ), supporting that only a moderate number of cases are required to reach this learning plateau. Whether very high experience by readers can further improve the performance could not be answered in our study and if advances in technology of MRI readings could further enhance the results remains to be evaluated.

Our study has several limitations. First, the study design was retrospective and readers were aware that most of the men had been subjected to prostatectomy. However, to reduce this potential bias, 11 biopsy-negative MRIs were added to the reading list. We acknowledge that this does not represent a clinical pre-biopsy situation but the reason for adding negative MRI:s was to reduce reader bias, not to create a substitute for a pre-biopsy setting. The biopsy-negative MRIs were excluded from the final analysis as they do not represent prostatectomy-confirmed true negatives.

Second, MRI was performed at different institutions with different protocols. The MRI protocol at the main site only included DWI imaging at b0 and b1500 due to hardware restrictions in MRI scanner. When calculating ADC-maps PIRADSv2.1 recommends using a maximum b-value of $\leq 1000 \mathrm{~mm} / \mathrm{s}^{2}$ to minimize the departure from basic monoexponential diffusion. We consider using b0 and b1500 for constructing the ADC-map a minor limitation. If ADC image data is used for visual inspection only and not for quantitative 
thresholding and analysis, tumour conspicuity will not decrease since ADC values will be lower on both tumour and normal peripheral zone. A bigger problem is low signal to noise when performing DWI at high b-values. A small number of examinations ( 3 in total) were excluded due to low DWI quality.

Third, a rather large proportion of examinations were performed without DCE (31\%). About 1/3 of these MRI:s were performed early in the study before the main site adopted mpMRI according to ESUR recommendations. There is a controversy regarding the diagnostic accuracy of bi-parametric prostate MRI (without DCE) in two recent meta-analyses reporting a slight advantage for multi-parametric MRI and no advantage, respectively $[27,28]$. However, the heterogeneity of the MRI population may be a strength since many hospitals in Scandinavia are not using DCE which brings this study closer to clinical routine. For the moderately experienced readers in this study, including bi-parametric MRI may have negatively affected cancer detection rates.

Fourth, although the PI-RADSv2 guidelines were recently published at the time of the retrospective review, it was decided in the study group to continue scoring each pulse sequence individually in the fashion of PI-RADSv1. However, the readers were aware of the update and the pictoral examples in the PI-RADSv2 document were used for reference. Finally, we did not include any expert readers as a reference but this may be a future study and a prospective study of low volume institutions with targeted biopsies as reference standard to evaluate if targeted biopsies outperform standard biopsies also in routine care.

In conclusion, in this study, prostate MRI evidenced a moderate detection rate for clinically significant PC. There is a rather large variability between readers which decreases if only PI-RADS 4 and 5 are considered. The variability outside specialized units makes it important for each unit to evaluate their own performance before they can safely use MRI in clinical routine to exclude men from undergoing prostate biopsies.

\section{Acknowledgements}

None of the sponsors had any part in the study design or access to the data nor had they any influence on or access to the analysis, the results, or the manuscript. We sincerely thank Ewa Löfkvist for her kind assistance in retrieving the pathology reports and Helén Ahlgren for her excellent help with database management. We also thank Karin Stinesen Kollberg for English language editing and review.

\section{Disclosure statement}

Sigrid V. Carlsson has received a lecture honorarium and travel support from Astellas Pharma (unrelated to current study). No potential conflict of interest was reported by the authors.

\section{Funding}

This work was supported by research grants from the Swedish Cancer Society (Contract number 2017/620), The Swedish Research Council [no. 2016-01973], and from the Swedish state under the agreement between the Swedish government and the county councils, the ALF- agreement [ALFGBG-724401 and ALFGBG-774531]. Part of Kimia Kohestanis work on this paper was supported by Anna-Lisa and Bror Björnsson's Foundation, Märta and Gustaf Ågren's Research Foundation, the Research Foundation at the Department of Urology at Sahlgrenska University Hospital, and the Royal and Hvitfeldtska Foundation. Sigrid V. Carlssons work on this paper was supported by research grants from the Sidney Kimmel Center for Prostate and Urologic Cancers, a Specialized Program of Research Excellence grant [P50-CA92629] from the National Cancer Institute to Dr. Howard Scher, a National Institutes of Health/ National Cancer Institute Cancer Center Support Grant [P30-CA008748] to Memorial Sloan Kettering Cancer Center, a grant from the National Cancer Institute as part of the Cancer Intervention and Surveillance Modelling Network [U01CA199338-02], and the David H. Koch prostate cancer research fund.

\section{References}

[1] Ferlay J, Steliarova-Foucher E, Lortet-Tieulent J, et al. Cancer incidence and mortality patterns in Europe: estimates for 40 countries in 2012. Eur J Cancer. 2013;49(6):1374-1403.

[2] The National Board of Health and Welfare Official stastistics of Sweden. Statistics on cancer incidence 2016 in Sweden 2017,December 31. Available from: https://www.socialstyrelsen.se/ Lists/Artikelkatalog/Attachments/20787/2017-12-31.pdf.

[3] Draisma G, Boer R, Otto SJ, et al. Lead times and over detection due to prostate-specific antigen screening: estimates from the European Randomized Study of Screening for Prostate Cancer. J Natl Cancer Inst. 2003;95(12):868-878.

[4] Sanchez-Chapado M, Olmedilla G, Cabeza M, et al. Prevalence of prostate cancer and prostatic intraepithelial neoplasia in Caucasian Mediterranean males: an autopsy study. Prostate. 2003; 54(3):238-247.

[5] Soos G, Tsakiris I, Szanto J, et al. The prevalence of prostate carcinoma and its precursor in Hungary: an autopsy study. Eur Urol. 2005;48(5):739-744.

[6] Telesca D, Etzioni R, Gulati R. Estimating lead time and overdiagnosis associated with PSA screening from prostate cancer incidence trends. Biometrics. 2008;64(1):10.

[7] Loeb S, Bjurlin MA, Nicholson J, et al. Overdiagnosis and Overtreatment of Prostate Cancer [Review]. Eur Urol. 2014;65(6): 1046-1055.

[8] Vårdprogramgruppen för prostatacancer Regionala cancercentrum i samverkan. Nationellt vårdprogram prostatacancer 2018, December 11 [2019-03-08]. Available from: https://www.cancercentrum.se/samverkan/cancerdiagnoser/prostata/vardprogram/ gallande-vardprogram-prostatacancer/.

[9] Ahmed HU, El-Shater Bosaily A, Brown LC, et al. Diagnostic accuracy of multi-parametric MRI and TRUS biopsy in prostate cancer (PROMIS): a paired validating confirmatory study. Lancet. 2017; 389(10071):815-822.

[10] Kasivisvanathan V, Rannikko AS, Borghi M, et al. MRI-Targeted or Standard Biopsy for Prostate-Cancer Diagnosis. N Engl J Med. 2018;378(19):1767-1777.

[11] Sonn GA, Fan RE, Ghanouni P, et al. Prostate magnetic resonance imaging interpretation varies substantially across radiologists. Eur Urol Focus. 2017;5(4):592-599.

[12] Futterer JJ, Briganti A, De Visschere $P$, et al. Can clinically significant prostate cancer be detected with multiparametric magnetic resonance imaging? A systematic review of the literature. Eur Urol. 2015;68(6):1045-1053.

[13] Moldovan PC, Van den Broeck T, Sylvester R, et al. What is the negative predictive value of multiparametric magnetic resonance imaging in excluding prostate cancer at biopsy? A systematic review and meta-analysis from the European Association of Urology Prostate Cancer Guidelines Panel. Eur Urol. 2017;72(2): 250-266. 
[14] Mottet N, Bellmunt J, Bolla $M$, et al. EAU-ESTRO-SIOG guidelines on prostate cancer. Part 1: Screening, diagnosis, and local treatment with curative intent. Eur Urol. 2017;71(4):618-629.

[15] Mottet N, Briers E, Cornford P, et al. EAU - EANM - ESTRO ESUR - SIOG guidelines on prostate cancer: EAU guidelines office, Arnhem, The Netherlands; 2019 [cited 28 June 2019]. Available from: https://uroweb.org/guideline/prostate-cancer/.

[16] Weinreb JC, Barentsz JO, Choyke PL, et al. PI-RADS prostate imaging - reporting and data system: 2015, Version 2. Eur Urol. 2016; 69(1):16-40.

[17] Mertan FV, Greer MD, Shih JH, et al. Prospective evaluation of the prostate imaging reporting and data system version 2 for prostate cancer detection. J Urol. 2016;196(3):690-696.

[18] Seo JW, Shin SJ, Taik Oh Y, et al. PI-RADS version 2: Detection of clinically significant cancer in patients with biopsy gleason score 6 prostate cancer. AJR Am J Roentgenol. 2017;209(1):W1-W9.

[19] Rosenkrantz AB, Ginocchio LA, Cornfeld D, et al. Interobserver reproducibility of the PI-RADS version 2 Lexicon: A multicenter study of six experienced prostate radiologists. Radiology. 2016; 280(3):793-804

[20] Kasel-Seibert M, Lehmann T, Aschenbach R, et al. Assessment of PI-RADS v2 for the detection of prostate cancer. European Journal of Radiology. 2016;85(4):726-731.

[21] Muller BG, Shih JH, Sankineni S, et al. Prostate cancer: Interobserver agreement and accuracy with the revised prostate imaging reporting and data system at multiparametric MR imaging. Radiology. 2015;277(3):741-750.

[22] Cohen J. A coefficient of agreement for nominal scales. Educational and Psychological Measurement. 1960;20(1):37-46.

[23] Greer MD, Brown AM, Shih JH, et al. Accuracy and agreement of PIRADSv2 for prostate cancer mpMRI: A multireader study. J Magn Reson Imaging. 2017;45(2):579-585.

[24] de Rooij M, Hamoen EH, Futterer JJ, et al. Accuracy of multiparametric MRI for prostate cancer detection: a meta-analysis. AJR Am J Roentgenol. 2014;202(2):343-351.

[25] Borofsky S, George AK, Gaur S, et al. What are we missing? Falsenegative cancers at multiparametric MR imaging of the prostate. Radiology. 2018;286(1):186-195.

[26] Rosenkrantz AB, Ayoola A, Hoffman D, et al. The learning curve in prostate $\mathrm{MRI}$ interpretation: self-directed learning versus continual reader feedback. AJR Am J Roentgenol. 2017;208(3): W92-W100.

[27] Niu XK, Chen XH, Chen ZF, et al. Diagnostic performance of biparametric MRI for detection of prostate cancer: a systematic review and meta-analysis. AJR Am J Roentgenol. 2018;211(2): 369-378.

[28] Kang Z, Min X, Weinreb J, et al. Abbreviated biparametric versus standard multiparametric MRI for diagnosis of prostate cancer: a systematic review and meta-analysis. AJR Am J Roentgenol. 2018; 4:W1-W9. 